\title{
Clinical and angiographic results after mechanical connection for distal anastomosis in coronary surgery
}

\author{
Thierry Carrel, MDa \\ Lars Englberger, MD \\ Dorothee Keller, $\mathrm{RN}^{\mathrm{a}}$ \\ Stephan Windecker, $\mathrm{MD}^{\mathrm{b}}$ \\ Bernhard Meier, $\mathrm{MD}^{\mathrm{b}}$ \\ Friedrich Eckstein, $M D^{\mathrm{a}}$
}

Background: Sutureless anastomotic devices are of increasing interest in cardiovascular surgery. We investigated the stainless steel clip system of St Jude Medical/ Anastomotic Technology Group (Maple Grove, Minn) to connect saphenous vein grafts with coronary arteries.

Methods: Forty-five patients were enrolled in this feasibility study performed on patients who had on-pump coronary artery bypass grafting, but 32 patients only received 1 distal anastomosis with this investigational device $(2.5 \mathrm{~mm}[\mathrm{n}=14]$ and $2.0 \mathrm{~mm}[\mathrm{n}=18])$. Thirteen were excluded because target vessels were too small, calcified, or tortuous. The system consists of an expandable clip mounted on a balloon catheter; delivery is obtained during balloon inflation. The main differences between the $2.5-\mathrm{mm}$ and $2.0-\mathrm{mm}$ devices are different loading and deployment in smaller coronary arteries for the $2.0-\mathrm{mm}$ device.

Results: A connecting device was deployed on the right coronary artery in 14 patients, the posterior descending branch in 12 patients, the obtuse marginal in 5 patients, and the posterolateral branch in 1 patient. Perfect hemostasis of the sutureless connector anastomosis was obtained in 28 patients. Three connectors were removed because of minor leakage at the connection site, and 1 connector was removed because of mismanipulation after successful deployment. Hand-sewn anastomosis was performed at the same arteriotomy site. Intraoperative flow was assessed by the transit time method and averaged $71 \pm 24 \mathrm{~mL} / \mathrm{min}$. One patient died of neurologic injury; the connector was patent at autopsy. One patient had a perioperative myocardial infarction. There was no adverse cardiac event in the remaining patients. All patients underwent clinical follow-up after 6 and 12 months and 35 angiograms were available in 21 patients: after 3 and 6 months, 17 anastomoses were patent and the saphenous vein graft was occluded in 4 patients.

From the Clinic for Cardiovascular Surgery $^{\mathrm{a}}$ and Division for Cardiology, ${ }^{\mathrm{b}}$ University Hospital Berne, Berne, Switzerland.

Read at the Twenty-ninth Annual Meeting of The Western Thoracic Surgical Association, Carlsbad, Calif, June 18-21, 2003.

Received for publication June 10, 2003; revisions requested Oct 7, 2003; accepted for publication Nov 4, 2003.

Address for reprints: Thierry Carrel, MD, Clinic for Cardiovascular Surgery, University Hospital, CH-3010 Berne, Switzerland (E-mail: thierry.carrel@insel.ch).

J Thorac Cardiovasc Surg 2004;127: 1632-40

$0022-5223 / \$ 30.00$

Copyright (C) 2004 by The American Association for Thoracic Surgery

doi:10.1016/j.jtcvs.2003.11.039

Conclusions: The coronary connector system from St Jude Medical/Anastomotic Technology Group allows consistently uniform sutureless connection between the saphenous vein graft and coronary artery. Loading and deployment require careful training. This technology is under constant development and may give a significant boost to less invasive coronary revascularization techniques.

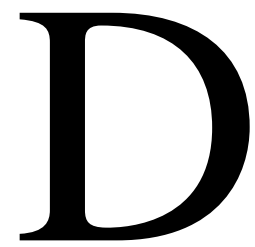

uring more than 3 decades, coronary artery bypass grafting $(\mathrm{CABG})$ has been performed through full sternotomy, with the aid of extracorporeal circulation and cardioplegic arrest as the treatment of choice for patients with multivessel coronary artery disease. Many patients who undergo this procedure today are older and sicker than in the past. For this reason, major efforts have focused on the development of innovative strategies to minimize general trauma due to the operation and to accelerate the patient's recovery. ${ }^{1-3}$ 
Developments in less invasive coronary surgery have been driven by the introduction of new technologies that should facilitate precise surgical maneuvers on the beating heart within confined spaces. Such technologies include coronary stabilizer systems, cardiac positioning vacuumassisted devices, and, to a lesser extent, telemanipulative technology. Despite these developments, suturing techniques using running polypropylene material remain the gold standard; however, sometimes these techniques limit the surgeon's ability to perform complete revascularization with high-quality anastomoses in a less invasive way. Suturing of small vessels is demanding and time-consuming and carries a learning curve but is adaptable to anatomic variations and vessel disease to achieve excellent patency.

Recently, the Anastomotic Technology Group (ATG) from St Jude Medical (Maple Grove, Minn) has developed a family of sutureless connectors that have the potential to facilitate the anastomosis of a vein graft to the ascending aorta (proximal connector) and between a vein graft and the coronary artery (distal connector). ${ }^{4,5}$ These connectors create a round side-to-side anastomosis, the diameter of which matches the internal diameter of the target coronary artery.

After extensive evaluation in cadaver hearts and animal models, ${ }^{6}$ we performed the first human implant of a distal connector successfully in November $2000 .^{7}$ This article presents clinical (6 and 12 months) and angiographic results (3 and 6 months) of 32 patients who received a distal connector for sutureless anastomosis between a saphenous vein graft and a native coronary artery.

\section{Methods}

The clinical protocol for the investigational trial with the first- and second-generation coronary connector systems was reviewed and approved by the Ethical Committee in Berne, Switzerland (no. 182/2000). This feasibility study was performed as a prospective, nonrandomized, open-label, single-center registry in patients scheduled for first-time CABG surgery using extracorporeal circulation with moderate hypothermia $\left(32^{\circ} \mathrm{C}-34^{\circ} \mathrm{C}\right)$ and cardioplegia during the construction of the distal anastomoses. Informed consent for 1 sutureless distal connection using this device was obtained in all patients.

Forty-five patients were preoperatively enrolled in this trial but 32 patients only received 1 distal sutureless connection with the first-generation $(2.5 \mathrm{~mm}, \mathrm{n}=14)$ or the second-generation (2.0 $\mathrm{mm}, \mathrm{n}=18$ ) device. Thirteen patients were excluded intraoperatively, mainly because the external diameter of the target coronary artery was smaller than that required $(<3.0 \mathrm{~mm}$ for the firstgeneration device, $<2.5 \mathrm{~mm}$ for the second-generation device) or because of calcified or tortuous coronary arteries. All patients received postoperative antiplatelet treatment with salicylic acid $(100 \mathrm{mg})$ and clopidogrel $(75 \mathrm{mg})$ daily, starting on the evening of the operative day.

\section{Loading and Delivery of the Device}

The distal coronary connector is made of stainless steel and contains small external hooks that are necessary to secure the vein

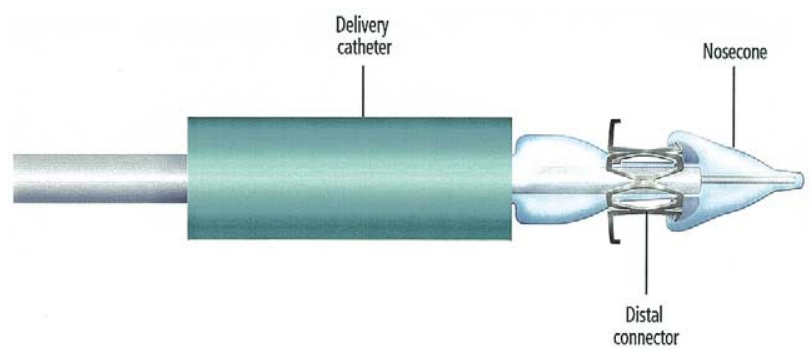

Figure 1. Distal connector system on the delivery catheter. Note that the first row of hooks for engagement into the coronary artery wall are covered by the nose cone to allow safe introduction of the device into the target coronary artery. (Reprinted with permission of St Jude Medical, Inc, St Paul, Minn.)

graft and internal fingers to engage in the coronary artery and hold the vein graft on the coronary artery once the connector has been deployed. The hooks, which will hold the wall of the coronary artery, are covered with a nose cone to protect the artery from injury during introduction of the device (Figure 1).

After harvesting of the saphenous vein graft (SVG; preferential inner diameter $>3.5$ to $4.0 \mathrm{~mm}$ ), a transfer sheet is introduced from the distal end backward into the graft. At the presumed site of the anastomosis, a small hole is created with a special blade. The delivery catheter is then introduced through the transfer sheet until the nose cone appears through the orifice. The entire circumference of the vein graft is distributed equally around the stainless steel connector, ensuring that the intima of the vein is placed over all external hooks. The vein is pierced through these 6 small hooks, and finally a small flexible rubber ring is slid over the nose cone and placed over the external hooks. This step that had to be performed under the microscope with $10 \times$ magnification was the major disadvantage of the first-generation system.

With the second-generation system, loading has been greatly simplified and therefore needs significantly less time. The delivery catheter is introduced into the distal end of the vein graft. The system is practically self-loading, which means that the delivery catheter with the connector on it can be introduced simply through the created hole in the vein graft. Piercing to secure the graft on the connector is no longer necessary as the angle and shape of the hooks were redesigned to adapt for self-attachment.

The process of delivery is similar for both systems. After the coronary artery has been pressurized with native blood flow or cardioplegic solution, a small arteriotomy blade is introduced tangentially in the coronary artery at the presumed site of connection. This incision is gently dilated with a standardized dilating tool that matches the hole in the coronary artery with the size of the preinflated delivery catheter. The delivery catheter is introduced into the coronary artery as axially as possible; the nose cone is advanced until the device adapts to the borders of the arteriotomy. While the delivery system is rotated up to a perpendicular position to the coronary artery, the balloon is inflated and pressurized to 18 atmospheres during 20 seconds. During this maneuver, the connector expands and reduces its length. The vein graft is compressed to the coronary artery (Figure 2). This step creates a hemostatic seal and firmly attaches the 2 vessels. Finally, the 
A

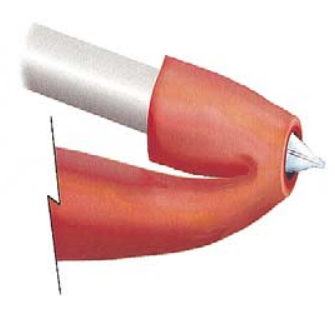

C

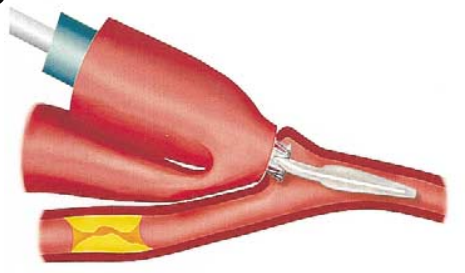

B

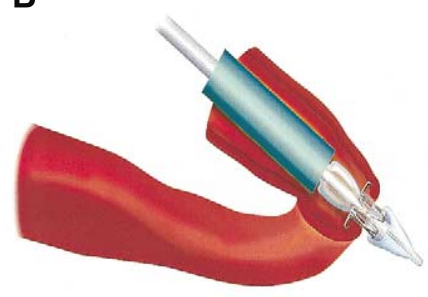

D

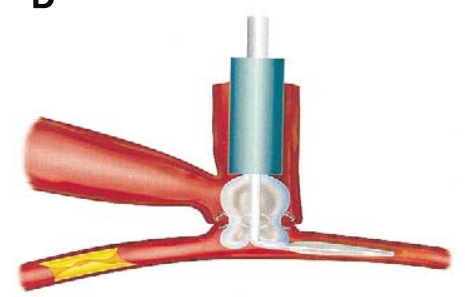

Figure 2. Main steps of introduction (A) and deployment (B) of the distal connector. Comparison of the firstgeneration device (C) and second-generation device (D) after completion of the anastomosis. (Reprinted with permission of St Jude Medical, Inc, St Paul, Minn.)
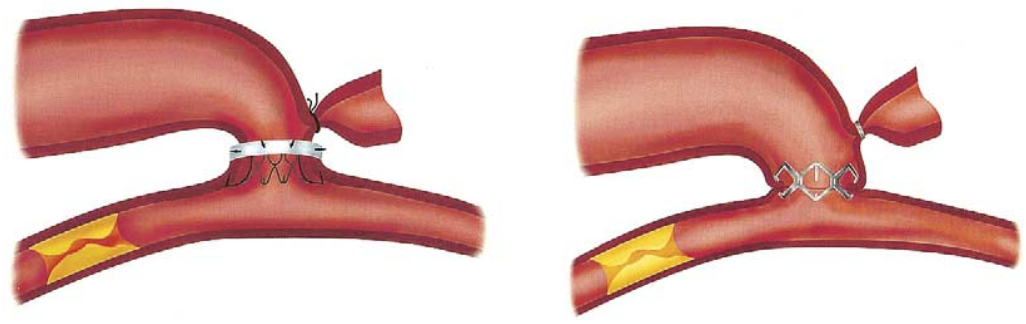

Figure 3. Anastomotic site with the first- and second-generation devices; note that piercing of the vein wall was necessary with the first-generation device. With the second-generation device, the wall of the vein graft and that of the coronary artery are only pushed together. (Reprinted with permission of St Jude Medical, Inc, St Paul, Minn.)

delivery catheter is removed and the distal end of the graft is closed with clips or sutures. Figure 3 shows the anastomotic connection and the differences between the first- and secondgeneration devices.

\section{Results}

The mean age of the patients was $67 \pm 4.5$ years; 28 were men and 4 were women. Twenty-five patients had a history of previous myocardial infarction, and mean preoperative New York Heart Association functional class was $2.8 \pm 0.5$. Mean preoperative left ventricular ejection fraction was $0.52 \pm 0.11$. Complete revascularization with at least 2 arterial grafts was performed in the majority of patients, and the mean number of distal anastomoses was 3.6 \pm 0.8 . One patient died of a neurologic injury, most probably due to atherosclerosis grade III of the ascending aorta. The connector was patent at autopsy. One patient had a perioperative myocardial infarction. No patient had connector-related morbidity and no major adverse cardiac events occurred during a follow-up of 12 months.

\section{Intraoperative Results}

Fourteen patients received a first-generation distal connector. Target coronary arteries were the right coronary artery in 10 patients, the posterior descending branch in 3 patients, and the obtuse marginal branch in 1 patient. Time to load the vein graft on the delivery system was between 6 and 8 minutes. Time to construct the connection was less than 2 minutes. Hemostasis was perfect in all cases. Mean bypass graft flow assessed after weaning from extracorporeal circulation with the transit time method (Medistim, Oslo, Norway) was $75 \pm 25 \mathrm{~mL} / \mathrm{min}$.

Eighteen patients received 1 distal anastomosis performed with the second-generation device. The target coronary artery was the right coronary artery in 4 patients, the posterior descending branch in 9 patients, the obtuse mar- 
ginal in 4 patients, and the posterolateral branch of the right coronary artery in 1 patient. Time to load the graft on the delivery catheter was significantly shorter $(<90$ seconds in the majority of patients). Time to create the connection was similar to that observed with the first-generation system. Hemostasis was perfect in $15(83.3 \%)$ of 18 cases, but in 3 patients some leakage appeared immediately after the construction of the anastomosis, while the graft was rinsed with blood cardioplegic solution. The connector was removed without problems in 2 patients, and hand-sewn anastomosis was performed at the same arteriotomy site using 7-0 polypropylene monofilament. In 1 patient, a localized coronary dissection was observed after removal of the device and the hand-sewn anastomosis was performed $1 \mathrm{~cm}$ distal to the original connection site, which was oversewn. In 1 patient, the connector, which was successfully inserted, was unfortunately pulled out during removal of a compress behind the heart at the end of the cardioplegic arrest period. Mean flow through the graft $(\mathrm{n}=14)$ was $71 \pm 18 \mathrm{~mL} / \mathrm{min}$.

\section{Immediate Postoperative Angiograms (First- Generation Device)}

All patients who received a first-generation device underwent complete coronary angiography at the end of the procedure, before admission to the intensive care unit. All anastomoses (those hand-sewn and those constructed with the connector) were patent and no narrowing was observed in any of them. In 1 patient who had triple CABG, the connection of the SVG with the device allowed antegrade flow into the distal right coronary artery only. This patient was returned to the operating theater immediately, and the connector that had back-walled the native coronary at the proximal angle of the connection was removed without difficulty. Hand-sewn anastomosis was performed with a running suture on the beating heart.

\section{Three-Month Angiograms (First-Generation)}

Angiograms $(11 \times)$ or magnetic resonance angiography $(1 \times)$ were available in 12 patients who received firstgeneration devices, although 2 patients refused invasive follow-up investigation. Altogether 54 anastomoses were evaluated; 41 from 43 hand-sewn anastomoses were patent, and 2 were occluded. One patent anastomosis had 30\% stenosis. Eleven grafts connected with the device were patent and 1 was occluded. In 3 patients, some narrowing at the site of the sutureless connection was suspected but no intervention was performed at this level in any patient. In 1 patient, the native right coronary artery was dilated and stented.

\section{Six-Month Angiograms (Second-Generation Devices)}

Angiograms were available in 10 patients; 3 patients refused invasive investigation despite having signed a consent form for it. A total of 35 anastomoses were evaluated. Of 25

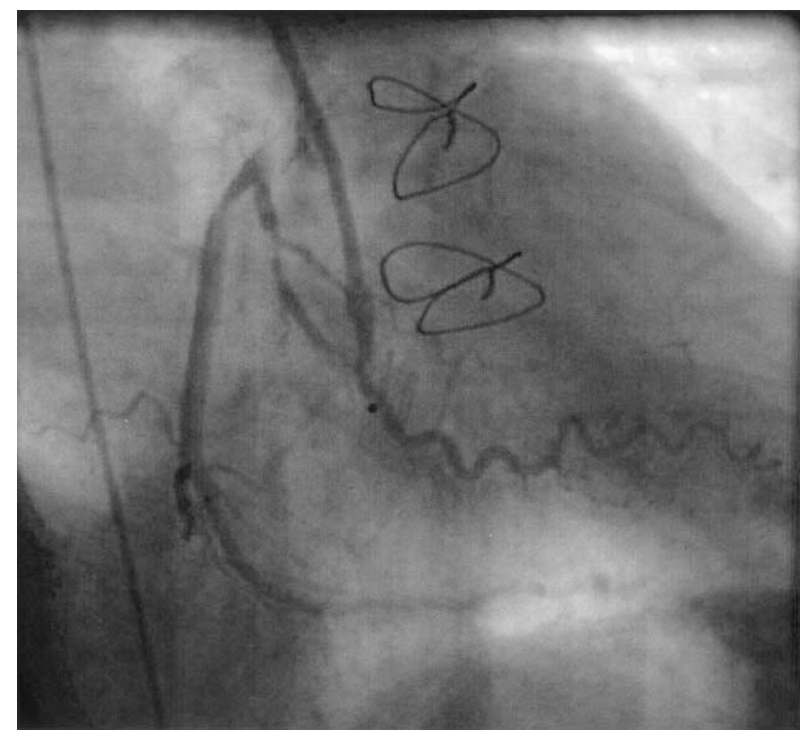

Figure 4. Six-month postoperative angiogram in a 68-year-old patient who underwent triple CABG. Note patent and normallooking anastomosis of the SVG to obtuse marginal branch. Additional SVG to posterolateral branch of right coronary artery and internal thoracic artery to left anterior descending coronary artery were patent.

hand-sewn anastomoses, 1 was occluded (SVG to first obtuse marginal branch) and 24 were patent. One internal thoracic artery-left anterior descending coronary artery anastomosis was successfully dilated because of a $50 \%$ to $70 \%$ stenosis. Three of 10 grafts with a distal connector were occluded. Interestingly, occlusion did not occur in those grafts with a poor intraoperative flow. Figure 4 shows a typical angiographic finding of a patent SVG to the circumflex artery with a connector device.

\section{Clinical Follow-up}

All patients who received 1 distal sutureless connection were evaluated clinically at 3, 6, and 12 months. All had undergone cardiac rehabilitation after the operation. No major adverse cardiac event or recurrence of angina occurred during the follow-up. Exercise tolerance test was negative in all patients.

\section{Discussion}

Current efforts to develop less invasive CABG have boosted a search for facilitated connections between bypass grafts, the aorta and the coronary vessels. Any alternative anastomotic technique to perform vascular connection needs to meet the same criteria of safety and long-term reliability as those obtained with the standard hand-sewn technique. Several distal anastomotic devices are currently under investigation but the long-term success of any of these devices has 
yet to be proved. ${ }^{8-18}$ Ideal characteristics of such devices should include applicability to all types of conduit independent of the size of the coronary arteries; they should be versatile in the sequence of the anastomosis and a safe bailout should be possible for device malfunction.

\section{Limitations From Own Experience}

An important limitation of the first-generation mechanical connector was the requirement that the target vessel be at least $2.5 \mathrm{~mm}$ in inner diameter, a situation not frequently encountered in the present era. The second-generation system presented in this article is applicable to smaller coronary arteries with an inner diameter of $2.0 \mathrm{~mm}$. Another important limitation was the fact that the first-generation connector had to be loaded outside of the operating field. The loading of the second-generation device has been greatly simplified, can be handled in the operating field, and allows versatility in the sequence of the anastomoses to be constructed. In addition, the distal anastomotic connector can be combined with a proximal vein graft connector to perform totally mechanical connected bypass grafts. As opposed to clips made of metal with memory function like nitinol, the use of stainless steel for coupling devices requires careful handling of the system during loading and delivery to avoid irreversible distortion. ${ }^{19-21}$

One failure was due to narrowing of the proximal coronary artery leading to unidirectional distal flow in this clinical series. This occurred early in our experience and was caused by capture of the posterior wall of the coronary artery by the internal hooks of the clip. This complication may develop if the diameter of the target vessel is rather small $(<1.5 \mathrm{~mm})$.

Some disadvantages may still be the complexity of the handling, the difficulty of use in difficult access target areas, and the absence of versatility in some devices (sequence of performing proximal and distal anastomoses not interchangeable). Most distal devices work only under the best of all circumstances, that is, in larger vessels (eg, >1.5-2.0 $\mathrm{mm}$ ) that have no disease. In the clinical practice most target vessels will not fulfill these criteria. In addition, a majority of devices are restricted to the use with vein grafts, which is not the goal that surgeons want to follow.

Data are lacking about the safety of a bailout: although some devices can be removed without difficulty, others may leave some damage on the target artery. In 1 case of unsuccessful delivery of the connector, bailout was easily possible and sutured anastomoses could be performed at the same arteriotomy site with running polypropylene suture. In the second series, we observed 1 localized coronary dissection after removal of the device. It was suspected that this complication occurred during introduction of the nose cone into the coronary artery.

\section{Size and Shape of the Sutureless Connection: Angiographic Findings}

Although the favorable effect of a compliant anastomosis has been demonstrated in several studies, a majority of the devices have a fixed opening, which might restrict the blood flow. ${ }^{22,23}$ Although some devices allow end-to-side anastomosis, the St Jude Medical device is conceived for side-toside anastomosis. Sequential anastomosis is technically feasible. The optimal size and the shape of a facilitated anastomosis has not been defined so far, and the tissue overgrowth at the anastomotic site has not been analyzed in depth.

It is self-evident that automatic connections of coronary vessels with a vein graft should be performed only with saphenous veins of adequate quality. Although the size of the vein does not influence the quality of the mechanical connection, the thickness of the wall is of utmost importance. In case of a very thin wall, there is some danger that the hooks are not anchoring the venous wall adequately, thus making the connection unstable during balloon inflation. When the graft presents with a thick wall, there is a potential danger that the wall of the graft may invaginate into the device itself, thereby decreasing the inner diameter of the connection.

The sutureless anastomoses produced by the distal St Jude Medical connectors are round and not oval, leading to the angiographic finding that they appear somewhat smaller (limited by the size of the connector) than hand-sutured anastomoses. The angiographic appearance may also appear unusual because of side-to-side connection at the end of the vein graft. The observed smooth narrowing in 3 anastomoses with the first-generation connector did not appear to restrict flow because the coronary flow reserve was normal in these grafts. However, the significance of these angiographic findings is still not clear and should be further investigated.

\section{Blood-Exposed Nonintimal Surface of Connecting Devices}

There might be some concern regarding use of connecting devices because a certain amount of foreign material is introduced into the coronary vessels. Although no intimal hyperplasia could be detected in long-term animal trials, ${ }^{6}$ long-term angiographic follow-up in humans are needed to confirm this finding. Animal studies demonstrated that only minimal foreign material surface is visible and in contact with the bloodstream in both generations of St Jude Medical connectors. Borst and colleagues ${ }^{24}$ have developed the BENIS (blood-exposed non-intimal surface) concept to compare the blood-exposed nonintimal surface in the anastomosis constructed with different connecting devices with the BENIS area in the hand-sewn anastomosis. In the majority of device-constructed anastomoses, the estimated minimal BENIS area ranged from 1 to $6 \mathrm{~mm}^{2}$ but was as high as 85 

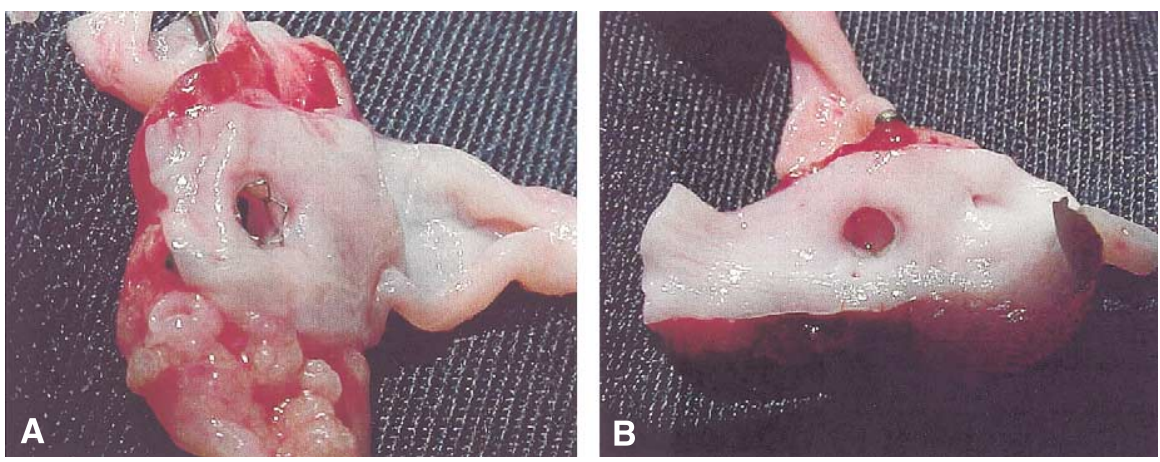

Figure 5. Ex vivo views of a distal anastomosis between SVG and left anterior descending coronary artery in the pig model (from the vein side of the anastomosis). Note the small amount of foreign material visible in the coronary artery $(A)$ and the perfect adaptation of vessel's intimal layers (B).

$\mathrm{mm}^{2}$ in one system, which means that a large amount of foreign material is exposed to the blood flow. ${ }^{24}$ In contrast, the conventional hand-sewn anastomosis shows a very small BENIS area of approximately $0.91 \mathrm{~mm}^{2}$. Therefore, large differences in potentially thrombogenic estimated BENIS area were found that are related to the location and size of the bonding components and to the size of the anastomotic orifice. When compared with other distal devices, the St Jude Medical connector has a favorable area, ranging between 3 and $4 \mathrm{~mm}^{2}$ (Figure 5). Unfortunately the BENIS concept has not been adopted so far by the industry.

Closed chest procedures using robotics for CABG are demanding and expensive procedures that require a long surgical learning curve because of the limited space in the operating field and the training required to carry out the technical manipulations. ${ }^{25,26}$

Industry is clearly driving the development and application of these anastomotic devices, using as principal argument that these systems may enhance the acceptance of less invasive CABG. However, there has been no evidence so far that using these devices speeds the anastomosis, particularly when the setup time is included; furthermore, none of the clinical trials (including the present one) has been able to demonstrate superior patency.

In conclusion, the hand-sewn distal bypass graft to coronary artery anastomosis represents a formidable gold standard that must be equaled or even improved on if any new sutureless technique has the goal to contribute to the progress of CABG. Any alternative to the manual anastomosis must fulfill standard requirements of precision and long-term patency rate, as well as simplification of the procedure. The family of St Jude Medical connector systems represents a step forward in this direction. ${ }^{27}$ With additional improvements, this promising technology will probably give a significant boost to less invasive coronary revascularization techniques.

\section{References}

1. Tasdemir O, Vural KM, Karagoz H, Bayazit K. Coronary artery bypass grafting on the beating heart without the use of extracorporeal circulation: a review of 2052 cases. J Thorac Cardiovasc Surg. 1998; 116:68-73.

2. Arom KV, Flavin TF, Emery RW, Kshettry VR, Janey PA, Peterson RF. Safety and efficacy of off-pump coronary artery bypass grafting. Ann Thorac Surg. 2000;69:704-10.

3. Taggart DP, Westaby S. Neurological and cognitive disorders after coronary artery bypass grafting. Curr Opin Cardiol. 2001;16:271-6.

4. Eckstein FS, Bonilla LF, Englberger L, Stauffer E, Berg T, Schmidli $\mathrm{J}$, et al. Minimizing aortic manipulation during OPCAB using the Symmetry ${ }^{\mathrm{TM}}$ Aortic Connector System for proximal vein graft anastomoses. Ann Thorac Surg. 2001;72:S995-8.

5. Eckstein FS, Bonilla LF, Englberger L, Immer F, Berg T, Schmidli J, et al. The St Jude Medical Symmetry ${ }^{\mathrm{TM}}$ Aortic Connector System for proximal vein graft anastomoses in coronary artery bypass grafting. J Thorac Cardiovasc Surg. 2002;123:777-82.

6. Schaff HV, Zehr KJ, Bonilla LF, Brennecke LH, Berg T, Cornelius R, et al. An experimental model of saphenous vein-to-coronary artery anastomosis with the St. Jude Medical stainless steel connector. Ann Thorac Surg. 2002;73:830-5.

7. Eckstein FS, Bonilla LF, Meyer B, Berg T, Neidhart P, Schmidli J, et al. Sutureless mechanical anastomosis of a saphenous vein graft to a coronary artery with a new connector device. Lancet. 2001;357:931-2.

8. Tozzi P, Corno A, von Segesser LK. Sutureless coronary anastomoses: revival of old concepts. Eur J Cardiothorac Surg. 2002;22:565-70.

9. Subramanian VA, Fonger JD, Connolly MW. Facilitated vascular anastomosis in coronary bypass surgery. Semin Thorac Cardiovasc Surg. 2002;14:89-100.

10. Carrel T, Eckstein F, Englberger L, Schmidli J, Berdat P. Clinical experience with devices for facilitated anastomoses in coronary artery bypass surgery. Ann Thorac Surg. 2004;77:1110-20.

11. Shennib H, Korkola SJ, Bousette N, Giaid A. An automated interrupted suturing device for coronary artery bypass grafting: automated coronary anastomosis. Ann Thorac Surg. 2000;17:312-8.

12. Solem JO, Boumzebra D, Al-Buraiki J, Nakeeb S, Rafeh W, Al-Halees Z. Evaluation of a new device for quick sutureless coronary artery anastomosis in surviving sheep. Eur J Cardiothorac Surg. 2000;17: 1046-8.

13. Hejimen RH, Hinchliffe P, Borst C, Verlaan CW, Moues CM, van der Helm YM, et al. A novel one-shot anastomotic stapler prototype for coronary bypass grafting on the beating heart: feasibility in the pig. J Thorac Cardiovasc Surg. 1999;117:117-25.

14. Gundry SR, Black K, Izutani H. Sutureless coronary artery bypass with biologic glued anastomoses: preliminary in vivo and in vitro results. J Thorac Cardiovasc Surg. 2000;120:473-7.

15. Martens S, Dietrich M, Doss M, Moritz A, Wimmer-Greinecker G. 
The Heartflo device for distal coronary anastomoses: clinical experiences in 60 patients. Ann Thorac Surg. 2002;74:1139-43.

16. Tozzi P, Solem JO, Boumzebra D, Mucciolo A, Genton CY, Chaubert $\mathrm{P}$, et al. Is the Graftconnector a valid alternative to running suture in end-to-side coronary arteries anastomoses? Ann Thorac Surg. 2001; 72:S999-1003.

17. Klima U, Falk V, Moritz A, Mohr FW, Haverich A, Wimmer-Greinecker G. Magnetic vascular coupling in coronary artery bypass grafting: a multicenter trial. J Thorac Cardiovasc Surg. 2003;126: 1568-74.

18. Buijsrogge MP, Scheltes JS, Heinkens M, Gründeman PF, Pistecky PV, Borst C. Sutureless coronary anastomosis with an automatic device and tissue adhesive in off-pump porcine coronary bypass grafting. J Thorac Cardiovasc Surg. 2002;123:788-94.

19. Hill AC, Maroney TP, Virmani R. Facilitated coronary anastomosis using a nitinol U-clip device: bovine model. J Thorac Cardiovasc Surg. 2001;121:859-70.

20. Berdat PA, Kipfer B, Immer FF, Pfammatter JP, Carrel T. Facilitated vascular interrupted anastomosis in cardiovascular surgery with a new clip device. J Thorac Cardiovasc Surg. 2002;124:1256-8.

21. Ono M, Wolf RW, Angouras D, Schneeberger EW. Early experience of coronary artery bypass grafting with a new self-closing clip device. J Thorac Cardiovasc Surg. 2002;123:783-7.

22. Baumgartner J. Influence of suture technique and suture material selection on the mechanics of end-to-end and end-to-side anastomoses. J Thorac Cardiovasc Surg. 1996;111:1063-72.

23. Stansby G, Knez P, Berwanger CS, Nelson K, Reichert V, SchmitzRixen T. Does vascular stapling improve compliance of vascular anastomoses? J Vasc Surg. 2001;35:115-21.

24. Borst C, Scheltes JS, van Andel CJ, Pistecky PV, Gründeman PF. Criteria to evaluate coronary anastomotic technologies. The Symmetry Meeting 2002; Evolution of Facilitated Anastomoses. Carlsbad, Calif, April 2002.

25. Boyd WD, Rayman R, Desai ND, Menkis AH, Dobkowski W, Ganapathy $\mathrm{S}$, et al. Closed-chest coronary artery bypass grafting on the beating heart with the use of a computer-enhanced surgical robotic system. J Thorac Cardiovasc Surg. 2000;120:807-9.

26. Mohr FW, Falk V, Diegeler A, Walther T, Gummert JF, Bucerius J, et al. Computer-enhanced robotic cardiac surgery: experience in 148 patients. J Thorac Cardiovasc Surg. 2001;121:842-53.

27. Eckstein FS, Bonilla LF, Englberger L, Eberli F, Windecker S, Berg TA, et al. First clinical results with a new mechanical connector for distal coronary artery anastomoses in CABG. Circulation. 2002; 106(Suppl I):1-4.

\section{Discussion}

Dr John C. Chen (Honolulu, Hawaii). Recent interest on offpump CABG has generated many spirited discussions. The introduction of epicardial stabilizers and blower devices in the mid1990s has changed the way CABGs are performed at many institutions. According to an article in the Wall Street Journal, approximately $20 \%$ of all coronary bypasses worldwide are performed by the beating heart technique. Are the new tools truly advancing our field of cardiac surgery or is this just early optimism from our industry partners? We will be reviewing data of on-pump versus off-pump later at this meeting. This may help to address whether doing it off-pump has been better for our patients. The completion of a perfect anastomosis is the holy grail of the coronary artery bypass operation. This is what I was taught in training. This is why interventional cardiologists refer patients to us for surgery. The hand-sewn vascular anastomosis is most demanding. Only the top guns of surgical residents have the privilege of ever flying solo. The ability to perform suture anastomosis accurately and quickly facilitates the performance of off-pump CABGs, especially when cardiac positioning results in hemodynamic com- promise. Until May 2000, the proximal aortic saphenous vein and the distal vein coronary anastomosis could be completed only by hand-suturing. Increasing interest in off-pump bypass has stimulated our industry partners to examine facilitating methods to create vascular anastomoses. Staples, clip, glues, laser welding, and coupling devices are competing for our attention. The replacement of a standard suture anastomosis by facilitating methods must not compromise graft patency, must produce at the very least comparable results, and must be easy to apply. Since US Food and Drug Administration approval in 2001, we have had experience with 95 proximal anastomotic devices at our institution. We continually evaluate outcomes as we gain experience with this device. The key issue surrounding distal anastomotic devices differs from those of the proximal device. The main driver for the use of the proximal device in our practice has been the calcified aorta. We would find the distal device helpful in facilitating minimal incision CABG. There are currently 4 distal connectors under clinical investigation: the Ventrica magnetic coupler (Ventrica, Inc, Fremont, Calif), the Joe-Med-Solem T-tube, the St Jude Medical balloon-expanded stent, and the Converge clip-based system.

Dr Carrel and his colleagues have just shared with us their experience with both first- and second-generation balloon-expanded stent devices for the distal saphenous vein-coronary anastomosis on-pump. I appreciate his sending me their manuscript before the presentation. They enrolled 45 patients in the trial, of whom 32 , or $71 \%$, were suitable for their distal connector device. I applaud this group for exploring this innovative off-pump technology on pump. They report intraoperative complications of anastomotic leakage occurring in 3 patients, coronary artery dissection in 1, and inadvertent device removal in another. My first question relates to intraoperative patient selection and device leakage. Dr Carrel, how did you decide who were the poor candidates for the distal device, which accounted for close to $30 \%$ of your patients? What prompted you to remove the device and sew the anastomosis in the 2 patients with leakage?

Dr Carrel. Thank you very much for this question. Despite having received informed consent we had to exclude some patients because the estimated size of the target coronary artery on the angiogram was not that found in the operative field. Therefore, in the patients who did not receive a distal connector, it was due to a diameter smaller than 3.0 or $2.5 \mathrm{~mm}$ in external diameter. Leakage was due to difficulties in pulling out the introducing catheter, but it is important to say that if the connector is leaking you can take it out very easily without any lesion to the arteriotomy size, and in the majority of cases you are able to perform a hand-sewn anastomosis at the same place. There was only 1 patient with a localized coronary dissection, probably due to a somewhat strong introduction of the nose cone at a calcified site of the coronary artery causing displacement of the plaque. In this patient we were not able to perform the anastomosis at the same anastomotic site so we had to close this arteriotomy and go $1 \mathrm{~cm}$ more distally. This was the only major event from a surgical point of view.

Dr Chen. That would certainly frighten me. In the text I noted that coronary angiograms were only performed on patients receiving the first-generation distal connectors, and 10 of the 14 patients were studied at 6-month follow-up. There has not been a clinical trial reported, including this one, that is able to demonstrate comparable results of connector devices to the hand-sewn anasto- 
mosis. In this series, of 25 hand-sewn anastomoses, 1 was occluded. In contrast, graft occlusion was seen in 3 of 10 patients receiving the distal connecting device. These patency results may be acceptable if the goal of the operation is to get a medically unstable, critically ill octogenarian with multiple life-limiting issues out of the hospital, but it appears to me that the firstgeneration distal balloon-expanded stent device has crashed and burned.

Dr Carrel, what is the metal-to-surface ratio of this distal connector device? What do you believe is the mechanism of the vein graft distal connector occlusion? Finally, what is the surgeon's responsibility to the patient as we explore future distal anastomotic systems?

Dr Carrel. Thank you very much. I think you raise very important technological and ethical points. It is clear that we have to be very careful, discussing also with cardiologists which kind of patient can be enrolled in such trials. That is the first issue. The second issue was my great surprise when I saw the different results obtained in the dog experiments in the Mayo Clinic and the preliminary clinical results. You know probably that Schaff and Zehr did a lot of work in dogs with these connectors and they had excellent results with minimal intimal hyperplasia and practically $95 \%$ patency at 6 or 12 months. Looking at the results we have obtained shows me that we cannot translate animal experiments into the clinical results. It might be due to the fact that dogs had healthy coronary arteries and we had to deal with very diseased coronary arteries and went quite distal. For instance, a majority of anastomoses were performed distal to the bifurcation of the right coronary artery. This might be an issue. We still speculate that perhaps the shape or the orientation of the anastomosis on the heart might not be the most optimal one. This is in contrast to the excellent intraoperative flow rates that we assessed just after the connection and after weaning the patient from bypass. We had no patient with a flow less than $40 \mathrm{~mL} / \mathrm{min}$, so we would have expected that these connections should remain open, but probably we have to speculate that some degree of very early narrowing happens, due to healing the processes or something else.

Dr Kenton Zehr (Rochester, Minn). You have basically answered in your last comment the question I had. Of course one of our major frustrations in working with the development of this device was that we could not take it to the clinical mode and so we have no clinical experience, but we have a fair bit of experience in both the porcine model and the canine model. That was precisely my question. Do you think that this was a major oversight in development of this device in overlooking the fact that we thought that you could translate this technique from normal canine coronaries to diseased, diffusely thick-walled vessels? Do you think that this technology can be developed and changed to fit the human model? Second, do you think that there is a difference in the amount of pseudointimal hyperplasia that the human creates against this device compared with the porcine or the canine model? I believe you have seen those data as well.

Dr Carrel. Thank you very much, Dr Zehr, for your appreciated comments. I must admit that I do not have a definite response. Of course, we were also surprised that angiograms taken at 3 months' follow-up showed some degree of narrowing in grafts that had been functioning perfectly during the operation, so we have to speculate that some kind of hyperplasia may have happened. We thought that the alignment of the anastomosis was good in all patients and this can be tested easily. Kinking was not an issue in this series of distal connection and probably not the reason for occlusion. What we have known, and this is a problem perhaps, is that it seemed that the venous endothelium is much more reactive to any kind of trauma than the endothelium of the radial artery and of the internal thoracic artery. We know this now from laboratory models. Perhaps the results will be more satisfying with another graft, but for this preliminary trial, we consider the venous graft as the gold standard, so that is the first graft to be compared if the technique of anastomosis is changed from hand-sewn to a mechanical one.

Dr Ralph Damiano (St Louis, Mo). I have a bit of a challenge and comment for you. I am not sure that all these devices, certainly the St Jude Medical even proximal connector, may not need to be considered for withdrawal from the market. More and more reports claim that these have both very high stenosis and higher than expected occlusion rates on the proximal side - not unexpectedly, in my opinion. They are stents, and stents restenose. However, the distal results here really seem to be very poor. In $20 \%$ of patients the device either leaked or caused a dissection, and then you have a $30 \%$ occlusion rate; these are very poor results and again not unexpected. We are exposing a stent, a stainless steel stent, to the open blood surface and endothelium. I think a very high rate of both stenosis and occlusion can be expected. I am very concerned. I would say we should probably be trying in cardiac surgery to use all arterial grafts in patients. That would do a great service, not trying to substitute a very good hand-sewn anastomosis with relatively inexpensive material for an expensive poor intracoronary or intra-aortic stent. That is my comment, and I think the audience should not get too carried away with this technology.

Do you really think that results with this exposed stent are ever going to be comparable with results obtained with hand-sewn anastomoses? Also, you just reported the number that were occluded, but I do not agree with you that those stenoses are just due to the fact that you have a built-in stenosis with the device. If that is true, that is wrong and I think you need to be much more clear-cut when presenting early technology. You should tell us how many of the grafts had over $50 \%$ stenosis, and the proximal connectors seemed to have an extremely high rate early on of around $20 \%$ to $40 \%$ stenosis. To me that is very, very worrisome. We are trying to do operations here. We are not cardiologists. I do agree, it looks like interventional cardiology, which I think is a big problem for us. We are trying to do an operation that should ideally last for 10 or 20 years, but are you concerned with this? What was the level of stenoses in these patients? I don't think you can argue away the fact that you have a built-in $50 \%$ stenosis, and that may not be so good for that patient in the long term.

Dr Carrel. Thank you very much. These critical comments are very appreciated because they highlight the main concerns that we should have with this new technology. Just to give you an answer concerning the proximal connector: we published a short article in the Annals titled "Pitfalls and key lessons with the symmetry proximal anastomotic device in coronary artery bypass surgery" (2003;75:1434-6), in which we described rates of stenosis. Of course I am still surprised that there was no major breakdown in the market expansion of the proximal first-generation device. At that time, we had not done quantitative angiographic measure- 
ments of the distal device, and that will be the next step, because in discussions about stenosis the terms should really be defined. The size of the connector is $2.0 \mathrm{~mm}$, and the diameter of the graft is usually 3.5 to $4 \mathrm{~mm}$. The aspect of the connection seems to be somewhat narrowed, but we had analyzed these results just superficially at that time. Therefore, the connection is smaller than the diameter of the graft, which is not usual when you construct an end-to-side hand-sewn anastomosis. In general, I fully agree with your comments. We do not have to repeat errors the cardiologists made 10 to 15 years ago. I think great care is needed here for further inclusion of patients. I'm not sure what the next-generation device will be. It might be oval or have a bigger connection, because otherwise we cannot go to smaller vessel diameters. However, even if the connection-related outcome was not spectacular at that time, the patient-related outcome was not adversely affected by the fact that some connections had to be removed and others occluded. No patient had any angina, infarction, or any other cardiac events during the follow-up. 